\title{
Research on Co-Movements Among Financial Markets of China and ASEAN Countries
}

\author{
Li Xinyu \\ Indiana University Bloomington, Kelley School of Business \\ 107 S Indiana Ave, Bloomington, IN, 47405, USA \\ lixinyu_christy@163.com
}

Key words: Stock market; Co-movement; Time variation; DCC-GARCH

\begin{abstract}
The economic ties between China and ASEAN get increasingly close, and the co-movement among the financial markets shows a significant character of time varying. With the daily data from 2012 to July, 2019, this paper gives an empirical analysis to the volatility spillover among the stock markets of China and six ASEAN countries, based on the multivariate DCC-GARCH model. The results manifest that there is significant volatility among the return rate of stock indexes of China and six ASEAN countries, and the volatility lasts. In addition, in the aspect of volatility spillover, the conditional correlation coefficients of China with six ASEAN countries are clearly time-varying; the correlation of China's stock market with Singapore's is the strongest and shows a rising tendency, while the correlation of China's stock market with Malaysia's and Thailand's is comparatively weaker and also shows a rising tendency, but in 2019 it is on the way down. The conditional correlation coefficients of China's stock market with the Philippines', Indonesia's and Vietnam's volatile frequently with same trend.
\end{abstract}

\section{Introduction and Literature Review}

The economic ties between China and ASEAN grow ever close. In 2018, China-ASEAN trade volume nearly reached 590 billion dollars. Among China's important trading partners, China's trade with ASEAN enjoys a strong growth. China has been ASEAN's biggest trading partner for ten consecutive years, and ASEAN has been the China's third biggest trading partner after the European Union and the United States. Due to the rise of American protectionism, in the first half of 2019, the trade volume between China and ASEAN has surpassed that between China and the United States, displaying a further strengthened economic relation between China and ASEAN. Finance is the barometer of economic development. Will the relation among financial markets of China and ASEAN countries change as their economic relation changes? The study on this question not only explores the time-varying character of the relation among financial markets of China and ASEAN countries, but also helps China and ASEAN countries practice joint intervention.

The existence of co-movement among different financial markets has been affirmed by many scholars (Hamao et al., 1990; Karim and Majid, 2010). Diebold and Yilmaz (2009) empirically analyzed the mean and volatility spillovers on the stock returns of 7 developed financial markets and 12 emerging financial markets. Teng et al. (2013) utilized the relevant data researches from 1991 to 2010, and pointed out the heterogeneity of the volatility spillover among stock markets of China and five ASEAN countries; but generally speaking, the co-movement among the financial markets of China and five ASEAN countries (Singapore, Malaysia, Indonesia, the Philippines and Thailand) grew stronger. Researches done by Chien et al. (2015) indicated that the financial integration of China and five ASEAN countries gained a further development step by step, but the empirical results only proved a clear co-integration relationship between financial markets of China and Indonesia.

It can be seen from the literature review that researches focusing on the co-movement among financial markets of China and ASEAN countries mainly took the five ASEAN countries as samples, and most of them selected co-integration analysis, Granger causality and error correction model as analyzing methods; and the results only disclose the mean spillover effect on return rate of the stock 
markets of China and ASEAN countries, but it failed to analyze the volatility spillover effect. Therefore, this paper takes the stock markets of China and six ASEAN countries as research objects and aims to give an empirical analysis to the dynamic correlation among financial markets of China and six ASEAN countries through multivariate DCC-GARCH model, which is the innovative point of this paper.

\section{Research Method and Data Declaration}

\subsection{Research Method}

As financial time series, the stock index return series often shows the characteristics of volatility clustering; that is to say, there is a significant heteroscedasticity in the stock index return series. In order to capture the volatility of a single stock index return series, this paper selects GARCH $(1,1)$ model to analyze individual stock return series by modeling conditional variance. As global financial markets become further integrated, volatility spillover exists among different stock markets, and also shows dynamic conditional correlation. In order to descript this, this paper utilizes multivariate DCC-GARCH model to empirically analyze the co-movement among stock markets of China and ASEAN countries.

\subsection{Data Declaration}

Considering the importance of Singapore, Malaysia, Indonesia, the Philippines, Thailand and Vietnam among ASEAN countries, this paper studies the co-movement of China's stock market with these six ASEAN countries'. In terms of stock indexes, the Shanghai Stock Exchange composite index (sse), Straits Times Index (sti), Kuala Lumpur composite index (klse), The Philippine Stock Exchange composite index (pesi), Jakarta Stock Exchange composite index (jkse), the Stock Exchange of Thailand index (set) and Vietnam index (vn) are chosen for the study, and the chosen data are the daily data from 2012 to July, 2019. The data source is https://cn.investing.com/indices . To start with, this paper takes the log of stock price indexes, and then calculates the first order difference, the calculating method is listed here:

$$
d \ln p_{t}=\ln p_{t}-\ln p_{t-1}
$$

The descriptive statistics of those indexes are listed in Table 1.

Table 1 The Descriptive Statistics of Those Indexes

\begin{tabular}{c|c|c|c|c|c|c|c}
\hline & $d \ln s s e_{t}$ & $d \ln s t i_{t}$ & $d \ln k l s e_{t}$ & $d \ln$ pesi $_{t}$ & $d \ln j k s e_{t}$ & $d \ln$ set $_{t}$ & $d \ln v n_{t}$ \\
\hline Mean & 0.0002 & 0.0001 & 0.0001 & 0.0004 & 0.0003 & 0.0003 & 0.0007 \\
Std & 0.0157 & 0.0082 & 0.0063 & 0.0116 & 0.0107 & 0.0097 & 0.0122 \\
Max & 0.0702 & 0.0544 & 0.0472 & 0.0554 & 0.0614 & 0.0460 & 0.0543 \\
Min & -0.1324 & -0.0569 & -0.0393 & -0.0918 & -0.0910 & -0.0774 & -0.0924 \\
Skew & -1.0924 & -0.1170 & -0.2742 & -0.6168 & -0.8327 & -0.7945 & -0.8367 \\
Kurt & 11.3614 & 7.4934 & 10.2050 & 8.5773 & 10.2997 & 9.9670 & 5.1275 \\
J-B & 4636.75 & 1256.91 & 3241.52 & 2025.64 & 3480.41 & 3170.23 & 1806.11 \\
P value & 0.0000 & 0.0000 & 0.0000 & 0.0000 & 0.0000 & 0.0000 & 0.0000 \\
\hline
\end{tabular}

From Table 1, it can be seen that during the sample period, all the mean values of individual stock return series are above 0 , all the skewness are below 0 , and all the kurtosis are beyond 3; the corresponding probability of the value of Jarque-Bera for normal distribution test is close to 0 . Therefore, the chosen 7 return series are in abnormal distribution, and show the characteristics of leptokurtosis and fat tail. Hence, the volatility of the series can be modeled.

\section{Empirical Analysis}

\subsection{Volatility Analysis of the Single Stock Market}

At first, the volatility of individual stock return series is modeled. Taking the autocorrelation of return series into consideration, $\mathrm{AR}(1)-\mathrm{GARCH}(1,1)$ model is built. The corresponding results are listed in Table 2. 
Table 2 The Estimation Results of Volatility in Single Stock Market

\begin{tabular}{ccccccccc}
\hline & $\mathrm{b}$ & $\mathrm{a}$ & $\mathrm{c}$ & $\alpha$ & $\beta$ & $\alpha+\beta$ \\
\hline$d \ln s s e$ & 0.0003 & $0.0464 *$ & $0.0000^{* *}$ & $0.0552^{* * *}$ & $0.9404^{* * *}$ & 0.9956 \\
& $(0.8416)$ & $(1.6665)$ & $(2.5401)$ & $(6.1793)$ & $(0.0091)$ & \\
$d \ln s t i$ & $0.0003^{*}$ & 0.0165 & $0.0000^{* *}$ & $0.0527 * * *$ & $0.9356^{* * *}$ & 0.9883 \\
& $(1.8525)$ & $(0.5983)$ & $(2.7356)$ & $(5.6581)$ & $(85.5035)$ & \\
$d \ln k l s e$ & 0.0001 & $0.0688^{* * *}$ & $0.0000^{*}$ & $0.0548^{* * *}$ & $0.9330^{* * *}$ & 0.9878 \\
& $(0.6363)$ & $(2.5870)$ & $(1.6771)$ & $(3.5497)$ & $(43.0925)$ & \\
$d \ln p s e i$ & $0.0007 * *$ & 0.0210 & $0.0000^{* * *}$ & $0.0634 * * *$ & $0.9179 * * *$ & 0.9813 \\
& $(2.5634)$ & $(0.7254)$ & $(3.0205)$ & $(5.0597)$ & $(61.2184)$ & \\
$d \ln j k s e$ & $0.0005 * *$ & -0.0005 & $0.0000^{* * *}$ & $0.0607 * * *$ & $0.9273 * * *$ & 0.9880 \\
& $(2.3533)$ & $(-0.0176)$ & $(3.0328)$ & $(5.8552)$ & $(80.5388)$ & \\
$d \ln s e t$ & $0.0005 * *$ & 0.0354 & $0.0000^{* * *}$ & $0.0611^{* * *}$ & $0.9294 * * *$ & 0.9905 \\
& $(2.5436)$ & $(1.1189)$ & $(2.8125)$ & $(5.2211)$ & $(69.8981)$ & \\
$d \ln v n$ & $0.0006 * *$ & $0.0805 * * *$ & $0.0000^{* * *}$ & $0.0853 * * *$ & $0.8856 * * *$ & 0.9709 \\
& $(2.3020)$ & $(2.3020)$ & $(2.8285)$ & $(6.2829)$ & $(43.9060)$ & \\
\hline
\end{tabular}

Note: numbers in parentheses refer to t-values, and $* * *, * *$ and $*$ refer to $1 \%, 5 \%$ and $10 \%$ levels of significance respectively.

In Table 2, a means first-order autoregressive estimated coefficients, $\alpha$ means estimated coefficients of ARCH, and $\beta$ means estimated coefficients of GARCH. It can be known from Table 2 that in the first-order autoregressive estimation, the first-order autoregressive coefficients of $d \ln k l s e$ be and $d \ln v n$ are significantly positive on the level of $1 \%$, the first-order autoregressive coefficients of $d \ln$ sse are significantly positive on the level of $10 \%$, but the estimated coefficients of the rest series are not significant. In the estimation of $\operatorname{GARCH}(1,1)$, the estimated values of $\alpha$ and $\beta$ are significantly positive, and the values of $\alpha+\beta$ are below 1 , which meets the requirement of $\operatorname{GARCH}(1,1)$ model. Meanwhile, the values of $\alpha+\beta$ are very close to 1 . This indicates the prominent volatility among the 7 return series, and the volatility lasts. Besides, GARCH $(1,1)$ model greatly helps to explain the volatility among individual stock return series.

\subsection{Time-varying Analysis of the Relation between China's Stock Market with ASEAN Countries'}

The estimation results of volatility in the single stock market provide the conditional variance of the return rate of each stock market of China and six ASEAN countries, which describes the risk in stock markets to a certain extent. But does financial risk conduct among stock markets? Especially when China-ASEAN relation becomes increasingly closer, is the co-movement among the financial markets of China and six ASEAN countries time-varying or not? In order to examine this, based on DCC-GARCH $(1,1)$ model, this paper does an empirical research to time variation of the stock markets of China and six ASEAN countries, and the estimated dynamic conditional correlation coefficients can be seen in Figure 1.

correlation of sse with sti

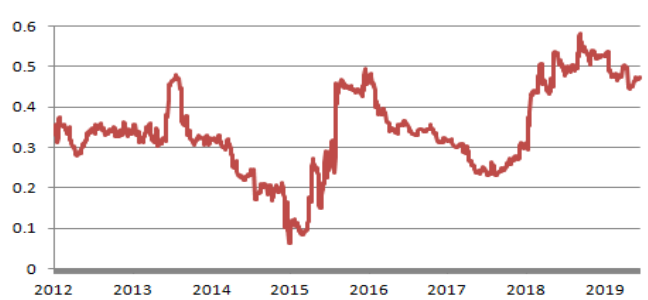

correlation of sse with klse

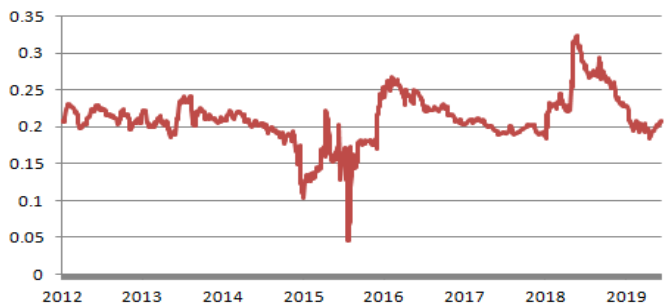



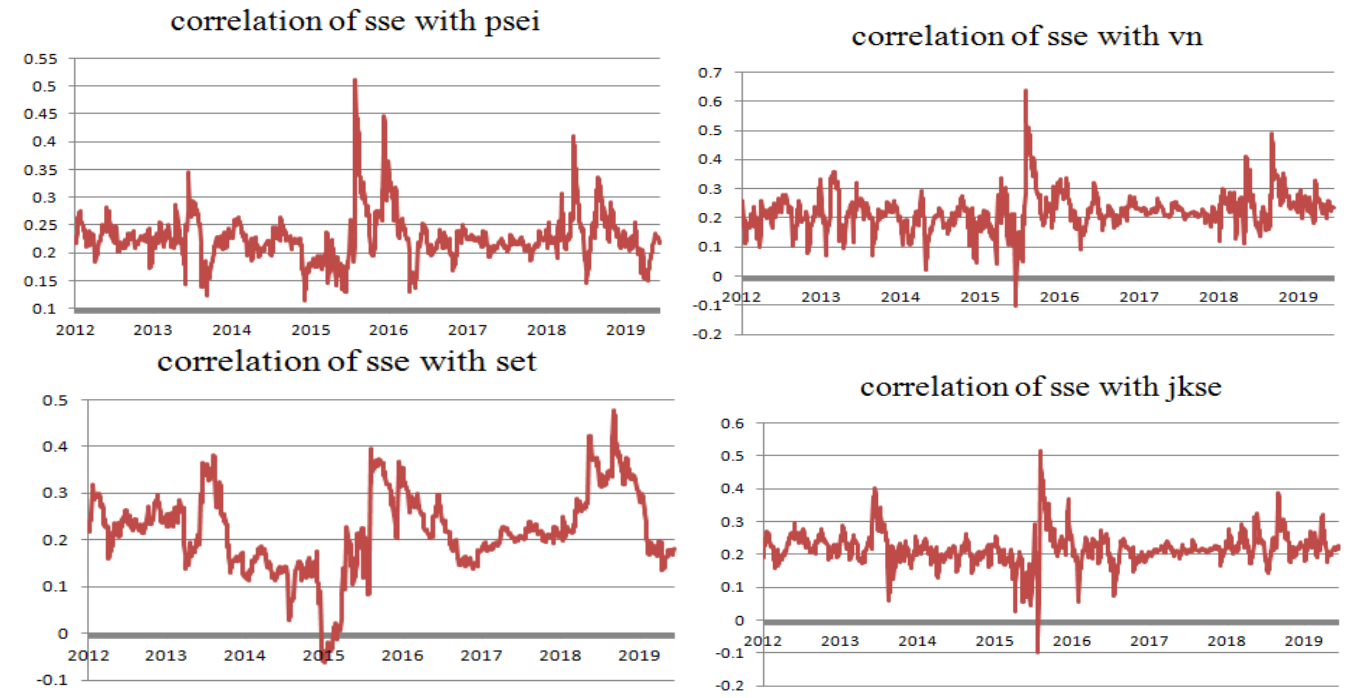

Figure 1 The Dynamic Conditional Correlation Coefficients of the Stock Markets of China and six ASEAN Countries

From Figure 1, it can be seen that the correlation of Shanghai Stock Exchange composite index (sse) with Straits Times Index (sti) is the strongest and obviously time-varying. During the period from 2012 to June, 2019, the correlation shows a down-up-down-up phase character, and in most of the period, the dynamic conditional correlation coefficients are beyond 0.3 . The dynamic conditional correlation coefficients of the Shanghai Stock Exchange composite index (sse) with the Philippine Stock Exchange composite index (pesi), Jakarta Stock Exchange composite index (jkse) and Vietnam index (vn) share a similar variation trend. In general, the three dynamic conditional correlation coefficients volatile frequently; in 2015, all of them show wild volatility, and the variation trend is of much similarity; besides, all of the three dynamic conditional correlation coefficients volatile around 0.2 . The volatility of the dynamic conditional correlation coefficients of the Shanghai Stock Exchange composite index (sse) with Kuala Lumpur composite index (klse) and the Stock Exchange of Thailand index (set) is comparatively flat on the whole, but in 2015 there was a serious decrease of both coefficients, and later they showed an up-down-up-down variation trend.

It can be known from the analysis to Figure 1, although the dynamic conditional correlation coefficients of China's stock market with the Philippines', Vietnam's and Indonesia's volatile repeatedly, all in all these coefficients remain low, which indicates the weak co-movement among the financial markets. The correlation of China's financial market with Malaysia's and Thailand's is very close, and displays a rising trend, but in 2019 there is a significant decrease. As developed financial market, Singapore's financial market has the strongest co-movement with China's.

\section{Conclusion}

As the business connection between China and ASEAN becomes closer and closer, the co-movement between the financial markets of China and ASEAN shows a distinct characteristic of time-variation. With the daily data from 2012 to July, 2019, this paper analyzes the volatility among the stock markets of China and six ASEAN countries (Singapore, Malaysia, the Philippines, Indonesia, Thailand and Vietnam), and empirically studies the dynamic conditional correlation among the return rate of the stock indexes of China and six ASEAN countries. The results manifest that in the terms of the return rate of the single stock market index of China and six ASEAN countries, volatility exists in the stock market and lasts. In the terms of the co-movement among the stock markets, there is significant volatility spillover among the stock markets of China and six ASEAN countries, and the conditional correlation coefficients are time-varying significantly. The information spillover between the stock markets of China and Singapore is the strongest. The correlation of China's stock market with Thailand's and Malaysia's is relatively weaker, but the trend is going up in general. Additionally, the co-movement among the stock markets of China, the 
Philippines, Vietnam and Indonesia is the weakest, and the dynamic conditional correlation coefficient volatiles around 0.2 frequently with rather consistent variation trend.

\section{Reference}

[1] Hamao Y., Masulis R.W., Ng V. Correlations in price changes and volatility across international stock markets [J]. Review of Financial Studies, 1990, 3(2):281-307.

[2] Karim B. A., Majid M. S. A. Does trade matter for stock market integration? [J]. Studies in Economics and Finance, 2010, 27(1): 47-66.

[3] Diebold F. X., Yilmaz K. Measuring financial asset return and volatility spillovers, with application to global equity markets[J]. The Economic Journal, 2019, 119(534): 158-171.

[4] Teng K.T., Yen S. H., Chua S. Y. The Synchronisation of ASEAN-5 Stock Markets with the Growth Rate Cycles of Selected Emerging and Developed Economies[J]. Margin: The Journal of Applied Economic Research, 2013, 7(1): 1-28.

[5] Chien M.S., Lee C.C., Hu T.C., Hu H.T. Dynamic Asian stock market convergence: Evidence from dynamic cointegration analysis among China and ASEAN-5[J]. Economic Modelling, 2015, 51: 84-98. 